\title{
Method of Static Characteristics Calculation of Vibroinsulators with Rectilinear and Circular Working Sections in a Non-Linear Approach
}

\author{
Alexander S. Gvozdev ${ }^{1} \&$ Vladimir S. Melentjev ${ }^{1}$ \\ ${ }^{1}$ Samara State Aerospace University (SSAU), 34, Moskovskoe shosse, 443086, Samara, Russia \\ Correspondence: Alexander S. Gvozdev, Samara State Aerospace University (SSAU), 34, Moskovskoe shosse, \\ 443086, Samara, Russia. E-mail: mtrushin@mail.ru
}

\author{
Received: July 28, $2014 \quad$ Accepted: August 4, $2014 \quad$ Online Published: February 26, 2015 \\ doi:10.5539/mas.v9n3p272 URL: http://dx.doi.org/10.5539/mas.v9n3p272
}

\begin{abstract}
An implementation of full-metal vibroinsulators is one of the most effective measures for an elimination of harmful effects of vibration in mechanical systems. However, in a contemporary literature an issue of an analytical calculation of vibroinsulators of that type, considering a non-linearity of the characteristics, is addressed insufficiently. In the presented study, by an implementation of exact theory of bending of elastic rods, the methodology of load characteristics calculation of full-metal vibroinsulators with elastic elements of rectilinear and circular shape of initial axial lines was developed. A groundlessness of Euler equation's implementation was demonstrated in a case of large displacement of linear rods, commensurable with their length. The method allows to increase designer's capabilities, to improve an accuracy of the calculation and to reduce time spent for a final adjustment of a product, which will ultimately lead to cost reduction final products.
\end{abstract}

Keywords: full-metal vibroinsulator, static characteristic, nonlinear elasticity theory, elastically damping element, elliptic parameters, elastic rod, elastic ring

\section{Introduction}

A number of papers is devoted to problems of vibration protection and energy dissipation (Ao et al., 2006; Popov, 1986; Belousov and Falaleev, 1989; Belousov et al., 2009; Chegodaev and Ponomarev, 1993; Jiang et al., 2008).

Nowadays, one of the most widely spread methods of vibration protection is an implementation of rope-type vibroinsulator based systems. Those vibroinsulators are more stable in an operation because contacts of their friction pairs are distributed along lines and areas (Ponomarev, 2003; Ulanov et al., 2009; Popp et al., 2003). Periodic structure of elastic elements facilitates a creation of more precise calculation models of vibroinsulators during their loading with various combinations of forces. Moreover, such vibroinsulators have advantage in contexts of cost and labor-intensity during production, in comparison with vibroinsulators of other types, for example, MR material based made from wire pressed together (Barry, 2014; Ulanov et al., 2009; Ao et al., 2006).

In studies of researchers who study problems of energy dissipation using structural damping methods (Ponomarev, 2003; Hakan, 2012; Jiang et al., 2008; Ulanov et al., 2009) with an implementation of similarity theory and dimensionalities a comprehensive analysis of possibilities for energy dissipation by various systems of vibration protection is presented: rope-type shock absorbers, shock absorbers made from pressed wire MR material, multilayer dampers with different diagrams of pressure between layers.

It is established, that multi-layer structures with an instantaneous slip with a uniform pressure between layers have the best damping properties, which allowed the authors to develop a number of highly effective damping devices' structures for aviation and machine building (Ponomarev, 2003).

Modern full-metal vibroinsulators belong to devices that sustain significant strain during their operation, which are commensurable with a size of elastic elements (Ponomarev et al., 2009; Belousov et al., 2009). In those circumstances there is a substantially non-linear dependence of large displacements from external forces, although a material of elastic elements of vibroinsulator behaves elastically because of small strains (Liu et al., 2010; Jiang et al., 2008; Ulanov et al., 2009). Therefore, linear theory of elastic rods bending gives a great inaccuracy in a case of vibroinsulators' design (Ponomarev, 2003; Popp et al., 2003; Jiang et al., 2008).

Different authors propose different theories of elastic rods' behavior under strains that cause significant strains, which are commensurable with their sizes (Zhdanov et al., 2013; Hakan, 2012). On a basis of theoretical 
position's data (Popov, 1986; Ponomarev, 2003; Barry, 2014; Ao, et al., 2006), in the presented study engineering methodology for a calculation of vibroinsulators static characteristics with rectilinear and circular working sections in a non-linear approach, which allows to greatly simplify a design for vibroinsulators of that type.

\section{Materials and Methods}

Designating expressions, describing bending of elastically damping element (EDE) in a form of a rectilinear elastic rod in a non-linear approach, using the dimensionless parameters (Note 1):

$$
\eta=\frac{P l^{2}}{E J}, \quad \varsigma=\frac{p}{l},
$$

where P - external load, 1 - characteristic size (in that case, length of rod), E - module of elasticity of material in bending, $\mathrm{J}$ - moment of inertia of cross-section of the rod, $\mathrm{p}$ - displacement (strain) due to external load.

From the classic strength of materials theory it is known that a strain of rectilinear rod is subjected to linear law.

Experiment data shows that, in fact, a functional dependence of displacements from external forces, especially in an area of large strain, is considerably non-linear. To consider that factor L. Euler proposed following equation:

$$
P=\frac{6 E J}{l^{2}(2 l-3 p)} p .
$$

By a reduction of (2) to dimensionless from, taking into account (1), obtaining

$$
\eta=\frac{6 \varsigma}{2-3 \varsigma} \text {. }
$$

However, it was determined experimentally that in Euler equation (2) non-linear nature of loading curves isn't described accurately enough. In this regard, the most reliable is a method of a calculation based on elliptic parameters proposed by E.P. Popov. According to that method, for a determination of rectilinear rod's static characteristics, a system of equations must be solved using tables of elliptic parameters' functions:

$$
\left.\begin{array}{l}
F\left(\psi_{1}\right)-F\left(\psi_{0}\right)=\beta \\
k \cdot \sin \psi_{0}=\sqrt{2} / 2 \\
2 k \cdot \cos \psi_{1}=0
\end{array}\right\} \quad,
$$

where $k$ - elliptic modulus, $\psi_{0}, \psi_{1}$ [psi] - initial and final amplitudes of Legendre elliptic integrals of first type $F\left(\psi_{0}\right), F\left(\psi_{1}\right)$.

Coordinates of final point 1 of an elastic rod are determined by following expressions.

$$
\left.\begin{array}{l}
\frac{x_{1}}{l}=\frac{2}{\beta} \cdot k \cdot \cos \phi_{0} \\
\frac{y_{1}}{l}=1-\frac{2}{\beta} \cdot\left[E(k)-E\left(\phi_{0}\right)\right]
\end{array}\right\},
$$

where $E(k), E\left(\phi_{0}\right)$ - Legendre elliptic integrals of second type, parameter $\varphi_{0}=\psi_{0}$.

Then, an equation of rod's elastic line will take following form

$$
\left.\begin{array}{l}
\frac{x}{l}=\frac{2}{\beta} \cdot k\left(\cos \phi_{0}-\cos \phi\right) \\
\frac{y}{l}=\frac{s}{l}-\frac{2}{\beta} \cdot\left[E(\phi)-E\left(\phi_{0}\right)\right]
\end{array}\right\},
$$

where $s$ - arc length to a desired point $\left(s_{\max }=0, s_{\min }=l\right)$.

A solution for a system of equations based on Legendre integrals of first and second kind allows to obtain an equation of rod's elastic line. Then a non-linear loading characteristic $\mathrm{P}=\mathrm{f}(\mathrm{p})$ will take a form, presented in figure 1 , and in that case $\mathrm{p}=\mathrm{y}_{1}$.

In order to bring desired parameters to dimensional type, using inverse transformation of the equation (1): 


$$
P=\frac{\eta \cdot E J}{l^{2}}, \quad p=\varsigma \cdot l
$$

Calculation research conducted by the authors and carried out in accordance with theory proposed by E.P. Popov, showed, that an actual loading characteristic lies in an area between classical linear strength of materials theory and L.Euler hypothesis (2) and the most accurately described by method of elliptic parameters. However, because of its high labor intensity that method has not yet been widely implemented. The authors had the objective- to find an alternative replacement for theory of E.P. Popov.

On the basis of L. Euler equation structure for an approximation of function $\eta=f(\varsigma)$ using least-squares method the following analytical expression was obtained, which is correct for any rectilinear EDE having cantilever type support (8):

$$
\eta=\frac{6 \varsigma}{2+0,015 \varsigma-2,312 \varsigma^{2}+0,793 \varsigma^{3}-\varsigma^{4}} .
$$

By substituting (1) in (8), obtaining:

$$
P=\frac{E J}{l^{2}}\left(\frac{6(p / l)}{2+0,015(p / l)-2,312(p / l)^{2}+0,793(p / l)^{3}-(p / l)^{4}}\right)
$$

The problem of strain of EDE in a shape of a ring is discussed further. Designating expressions, describing bending of EDE in a shape of a ring in a nonlinear approach. The equation (1), in that case, becomes:

$$
\eta=\frac{Q \pi^{2} R^{2}}{8 E J}, \quad \varsigma=\frac{q}{R},
$$

where $\mathrm{Q}=2 \mathrm{P}$ - compressing (stretching) forces, $\mathrm{R}$ - radius of middle line of circular EDE, $\mathrm{q}$ - displacement (strain) due to force $\mathrm{Q}$.

According to classis theory of strength of materials, deformation of ring is described by the following expression:

$$
q=\left(\frac{\pi}{2}-\frac{4}{\pi}\right) \cdot \frac{P R^{3}}{2 E J}
$$

In a nonlinear approach, for a determination of static characteristics of discussed EDE, according to E.P. Popov, it is sufficient to analyze two forms I, II of elastic line of contnuous thin ring with radius $\mathrm{R}$ in a case of its bending by two mutually equipoise radially compressing forces $\mathrm{Q}$. Considering that form I can pertain to inflection (form $\mathrm{I}_{1}$ ) and noninflection (form $\mathrm{I}_{2}$ ) type, obtaining a system of equations, expressed through elliptic parameters, which is describing forms of elastic line of analyzed ring in axes', $y^{\prime}$, where axis $x^{\prime}$ is directed along the external force $\mathrm{P}=\mathrm{Q} / 2$, of a local coordinate system:

$$
\begin{aligned}
& I_{1}:\left\{\begin{array}{l}
\frac{x^{\prime}}{R}=\frac{2}{k \beta_{0}} E(\phi)-\left(\frac{2}{k^{2}}-1\right) \frac{s}{R}, \\
\frac{y^{\prime}}{R}=\frac{2}{k \beta_{0}}\left(1-\sqrt{1-k^{2} \sin ^{2} \phi}\right),
\end{array}\right. \\
& I_{2}:\left\{\begin{array}{l}
\frac{x^{\prime}}{R}=\frac{2}{\beta_{0}} E(\phi)-\frac{s}{R}, \\
\frac{y^{\prime}}{R}=\frac{2}{\beta_{0}} k(1-\cos \phi),
\end{array}\right.
\end{aligned}
$$




$$
I I:\left\{\begin{array}{l}
\frac{x^{\prime}}{R}=\frac{2}{\beta_{0}} E(\phi)-\frac{s}{R}, \\
\frac{y^{\prime}}{R}=\frac{2}{\beta_{0}} k(1-\cos \phi) \text { when } 0 \leq s \leq s_{i . p}, \\
\frac{x^{\prime}}{R}=\frac{2}{\beta_{0}}[2 E(k)-E(\phi)]-\frac{s}{R}, \\
\frac{y^{\prime}}{R}=\frac{2}{\beta_{0}} k(1+\cos \phi) \text { when } s_{i . p} \leq s \leq \frac{\pi R}{2}
\end{array}\right.
$$

Where $s_{\text {i.p }}$ - inflection point of elastic line.

By changing to $\mathrm{xCy}$ coordinate systems, which are related with a ring's center $\mathrm{C}$, for forms I and II obtaining:

$$
\text { I and II: } x=x^{\prime}, y=y_{1}^{\prime}-y^{\prime} \text {. }
$$

Creating a static characteristic (see Figure 2 ) in the form of a relationship between $\mathrm{Q}=\mathrm{f}(\mathrm{q})$, where $\mathrm{q}$ is a displacement of force $\mathrm{Q}$, at that

$$
Q=2 \beta_{0}^{2}\left(E J / R^{2}\right),
$$

For forms I, II obtaining:

$$
\text { where } \beta_{0}=(2 / \pi) \beta
$$

$$
q=R-x_{1}=R-x_{1}^{\prime} .
$$

In order to bring desired parameters to a dimensional form, using inverse transformation of the equation:

$$
\begin{aligned}
& Q=\frac{8 \eta \cdot E J}{\pi^{2} R^{2}}, \\
& q=\varsigma \cdot R .
\end{aligned}
$$

Determining power coefficient of similarity $\eta$ [eta] dependence from dimensionless strain $\varsigma$ [zeta], using the methodology proposed by the authors, in a form of a polynomial expression:

$$
\eta=\sum_{i=1}^{3} k_{i} \cdot \varsigma^{i}
$$

At the same time, in order to ensure a succession of linear theory (11), presenting coefficient near first member of expansion in the form $\left(\frac{4 \pi}{\pi^{2}-8}\right)$.

In that case (19) will take following form:

$$
\eta=\frac{4 \pi}{\pi^{2}-8} \cdot \varsigma-5,693 \varsigma^{2}+3,298 \varsigma^{3} .
$$

By substituting expressions (10) in the expression (20), finally obtaining expression, which is correct for any circular EDE:

$$
P=\frac{E J}{R^{2}}\left[\left(\frac{4 \pi}{\pi^{2}-8}\right) \cdot \frac{q}{R}-5,693\left(\frac{q}{R}\right)^{2}+3,298\left(\frac{q}{R}\right)^{3}\right]
$$

In order to illustrate the proposed engineering methodology the authors determined loading characteristic in a vertical direction of vibroinsulator, presented in Figure1a.

That vibroinsulator consists of four EDE in a form of cable segments (rods), which ends are anchored in intermediate elements, made in the a form of two brackets, having two clamps each for installation of cables in them, and in one bracket cable is installed using rigid fastening, in another it is movable and mounted on the brackets in such a manner that every cable has one fastening point with each bracket. 


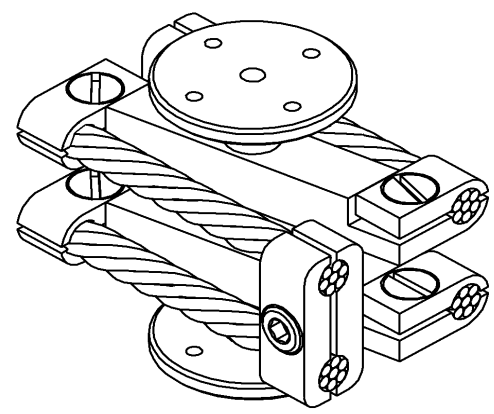

a)

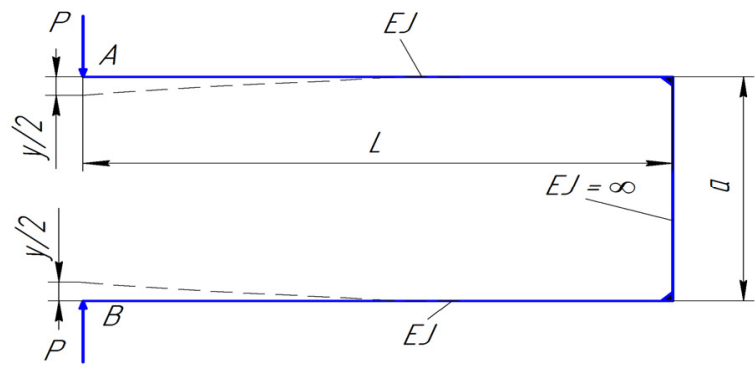

b)

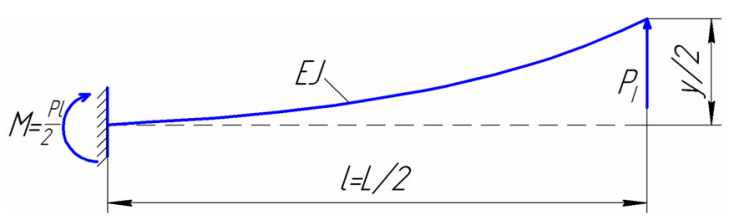

c)

Figure 1. Vibroinsulator

$\mathrm{a}$ - vibroinsulator with rectilinear EDE; b - equivalent calculation scheme; c - calculation scheme of vibroinsulator.

Calculation scheme of vibroinsulator is shown in Figurelb. By defining inflection of a frame's end as $y / 2$, obtaining total displacement of points $\mathrm{A}$ and $\mathrm{B}$ relative to each other equal to $\mathrm{y}$. Considering that the angle of rotation in points $\mathrm{A}$ and $\mathrm{B}$ is equal to zero, calculation diagram of cantilever beam will be equivalent to zero (Figure 1c). For one frame, the basic parameters are presented as

$$
\begin{gathered}
\qquad \delta=\frac{y}{2}, \quad l=\frac{L}{2}, \quad \varsigma=\frac{2 y}{2 L}=\frac{y}{L}, \\
\text { obtaining } P_{I}=\frac{E J}{(L / 2)^{2}}\left[\frac{6 \varsigma}{2+0,56 \varsigma-4,76 \varsigma^{2}+2,36 \varsigma^{3}}\right]
\end{gathered}
$$

or

$$
P_{I}=\frac{4 E J}{L^{2}}\left[\frac{6(y / L)}{2+0,56(y / L)-4,76(y / L)^{2}+2,36(y / L)^{3}}\right]
$$

Because two frames are working in a vibroinsulator simultaneously, then

$$
P_{\Sigma}=2 P_{I}=\frac{8 E J}{L^{2}}\left[\frac{6(y / L)}{2+0,56(y / L)-4,76(y / L)^{2}+2,36(y / L)^{3}}\right]
$$


Since in vibroinsulator two frames operate simultaneously, an equation that allows to create static characteristics of any vibroinsulators of that type, have a following form (30).

With an implementation of developed calculation methods parameter series of rope-type vibroinsulators are created for loads from 0.1 to $100 \mathrm{~kg}$ with rectilinear, radial and spatial shapes of elastic lines.

Range of loads is divided on areas according to law of geometric sequence.

Inside each area, optimal loads were selected according to law of geometric sequence. Rigidity of vibroinsulators was determined with a condition of a provision of system's natural frequency of $10 \mathrm{~Hz}$, according to recommendations for devices and equipment of airspace engineering. Standard arrangements were used of transversal cross-sections of ropes. A determination of geometric parameters and physical characteristics of vibroinsulators was carried out on a basis of obtained criterion expressions, in which values of dimensionless criterion were selected according to conditions of a provision of reliability, manufacturability, minimal weight and dimensions.

\section{Results}

The presented study conducted by the authors allowed to obtain following results.

1. Following analytical expression of loading characteristics was obtained, which is correct for any rectilinear EDE having cantilever-type support in a dimensionless form:

$$
\eta=\frac{6 \varsigma}{2+0,015 \varsigma-2,312 \varsigma^{2}+0,793 \varsigma^{3}-\varsigma^{4}}
$$

and in dimensional form:

$$
P=\frac{E J}{l^{2}}\left(\frac{6(p / l)}{2+0,015(p / l)-2,312(p / l)^{2}+0,793(p / l)^{3}-(p / l)^{4}}\right)
$$

In Figure 2 a comparison of loading characteristics is presented, which is created on the basis of the authors methodology, classical linear elasticity theory and the methods of E.P. Popov and L. Euler.

2. The expression is obtained, which is correct for any circular EDE in dimensionless form

$$
\eta=\frac{4 \pi}{\pi^{2}-8} \cdot \varsigma-5,693 \varsigma^{2}+3,298 \varsigma^{3} .
$$

and in dimensional form

$$
P=\frac{E J}{R^{2}}\left[\left(\frac{4 \pi}{\pi^{2}-8}\right) \cdot \frac{q}{R}-5,693\left(\frac{q}{R}\right)^{2}+3,298\left(\frac{q}{R}\right)^{3}\right]
$$

In Figure 3 a comparison of loading characteristics is presented, created on the basis of the authors' methodology, classical linear elasticity theory and the method of E.P. Popov.

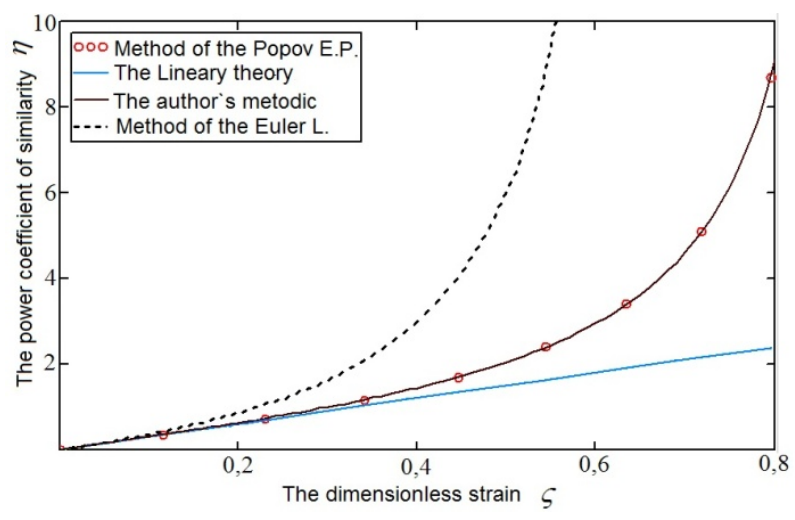

Figure 2. Diagram of static characteristic of rectilinear elastic rod 


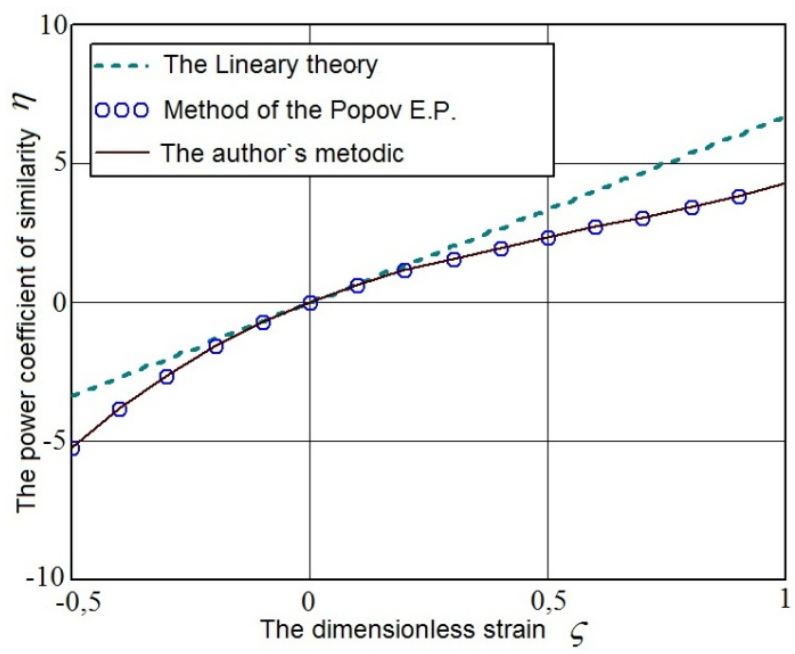

Figure 3. Diagram of static characteristic of elastic ring

3. Loading characteristic is obtained

$$
P_{\Sigma}=2 P_{I}=\frac{8 E J}{L^{2}}\left[\frac{6(y / L)}{2+0,56(y / L)-4,76(y / L)^{2}+2,36(y / L)^{3}}\right]
$$

which allows to create static characteristics of any vibroinsulators of a form factor, presented in Figure 1.

\section{Discussion}

The fact that it is impossible to use a classical strength of materials theory and hypotheses of L. Euler for a calculation of loading characteristics of EDE, subjected to strain, which is commensurable with their size was established and experimentally confirmed (Ponomarev, 2003; Ao et al. 2006; Jiang et al., 2008; Barry, 2014). In that case, the most accurate is the method of calculation based on elliptic parameters and considering significant nonlinearity of strain process (Popov, 1986). However, labor-intensiveness of that method does not allow to freely use it in engineering practice (Ponomarev et al., 2013). The proposed engineering method is based on the same principles, but it is much easier to implement, therefore, it can be used as an alternative replacement.

The discussed method has a number of advantages as compared to finite-element method. First, it is an increased speed of calculation, because a creation of detailed analytical model isn't required. Second, there is a possibility to directly determine a rational ratio for a designed product, by analyzing obtained criterion equation without a search of various variants.

It was experimentally confirmed that discussed method allows you to increase designer's capabilities, increase scientific and technological level of design process, reduce time spent on final adjustments of a product (Belousov et al., 2009; Ulanov, 2009), as well as to use more precise models of vibroinsulators in dynamical calculations (Jiang et al., 2008; Yurddas et al., 2014), which will ultimately lead to a cost reduction of finished products.

\section{Conclusion}

It should be noted that the information provided in the presented paper does not cover the entire range of objectives, which a researcher accomplishes in the process of a creation of the method for a calculation of static characteristics of full-metal vibroinsulators.

A further direction of the research, in the authors opinion, is connected with a study of more complex forms of elastic elements in order to analyze phenomena such as, for example, quasi zero rigidity in structures, equal frequency of rigid element by coordinate axes and a regulation in vibroprotective systems.

Another important direction of research can be a deeper investigation of damping properties of discussed structures. It is necessary to note, that currently damping is studied to a sufficient degree only in elements with periodic structure, such as laminar structures. That problem is more topical in a field of study of vibroprotective devices with rope-type elements. Nowadays, similar to functional relationships, which are true for pressed wire MR material, for rope-type elements averaged damping coefficients are used, which are obtained by 
experimental data processing. Apart from the fact, that damping coefficient is changing with time, it can be influenced by many parameters (rope coiling angle, value of wire's tightening, manufacturing coatings and lubricants, etc.), which are hard to account. That, in turn, doesn't allow to create logically complete method, which includes mass production technology of precision full-metal vibroinsulators of that type. For vibroprotective systems acceptable solutions in dimensionless form haven't been found so far.

\section{Acknowledgements}

The presented study was supported by the Ministry of education and science of the Russian Federation in a framework of Program for an increase of competitiveness of SSAU among the world's leading scientific and educational centers for 2013-2020 years.

\section{References}

Balyakin, V. B., Falaleev, S. V., \& Novikov, D. K. (2002). Air-tightness of secondary gas end seal assembly. Gazovaya Promyshlennost, 8, 56-58.

Barry, O., Zu, J. W., \& Oguamanam, D. C. (2014). Analytical and experimental investigation of overhead transmission line vibration. Journal of Vibration and Control. WOS: 1077546313517589.

Belousov, A. I., \& Novikov, D. K. (1986). Selection of GTE rotor bearing hydrodynamic damper type. Soviet Aeronautics (English translation of Izvestiya VUZ, Aviatsionnaya Tekhnika), 29(3), 6-10.

Belousov, A. I., \& Falaleev, S. V. (1989). Gasostatic face seal with elastic working surface. Soviet Journal of Friction and Wear (English translation of Trenie i Iznos), 10(3), 34-38.

Belousov, A. I., Novikov, D. K., \& Eskin, I. D. (1981). Theory of hydrodynamic dampers with cylindrical and end slots. Soviet Aeronautics (English translation of Izvestiya VUZ, Aviatsionnaya Tekhnika), 24(3), 13-17.

Belousov, A. I., Balyakin, V. B., \& Novikov, D. K. (1985). Experimental study in pressure distribution in the oil film of short hydrodynamic damper. TRENIE \& IZNOS, 6(4), 648-652.

Belousov, A. I., Balyakin, V. B., \& Novikov, D. K. (1985). Experimental study of pressure distribution in lubricant layer of 'short' hydrodynamic dampers. Soviet Journal of Friction and Wear (English translation of Trenie i Iznos), 6(4), 56-59.

Belousov, A. I., Ponomarev, Y. K., Yu., Pronichev, N., \& Krypaev, D. G. (2009). Theory of an annular corrugated damper in the vibrator precession motion. Russian Aeronautics, 52(2). Date Views 17.02.2014 http://dx.doi.org/10.3103/S1068799809020111

Chegodaev, D. E., \& Ponomarev, Y. K. (1993). Multilayer shock absorbers with controllable elastic hysteresis characteristics. Izvestiya Vysshikh Uchebnykh Zavedenij. Aviatsionnaya Tekhnika, 2, 63-67.

Hakan, Y., Selçuk, M., \& Sadettin, K. (2010). Hybrid input shaping to suppress residual vibration of flexible systems. Journal of Vibration and Control, 18, 132. http://dx.doi.org/10.1177/1077546311403179

Hongrui, A., Jiang, H. Y., \& Ulanov, A. M. (2006). Estimation of the fatigue lifetime of metal rubber isolator with dry friction damping. Experimental Mechanics in Nano and Biotechnology, Parts 1 and 2, Vol. 326-328, 949-952. WOS: 000243448201010.

Hongrui, A., Jiang, H. Y., Wei, W., \& Ulanov, A. M. (2006). Study on the damping characteristics of MR damper in flexible supporting of turbo-pump rotor for engine. ISSCAA 2006: 1st International Symposium on Systems and Control in Aerospace and Astronautics, Vol. 1-2, 618-622. WOS: 000237415000129.

Jiang, H. Y., Zhang, R. H., Zhao, K. D., \&. Novikov, D. K (2005). Analysis of damping characteristics of squeeze film damper with metal rubber. Tuijin Jishu/Journal of Propulsion Technology, 26(2), 174-177.

Jiang, H. Y., Hao, D. G., Xia, Y. H., Ulanov, A. M., \& Ponomarev, Y. K. (2008). Damping characteristics calculation method of metal dry friction isolators. Journal of Beijing Institute of Technology (English Edition), 17(2), 173-177.

Liu, T. Y., Chiang, W. L., Chen, C. W., Hsu, W. K., Lu, L. C., \& Chu, T. J. (2010). Identification and monitoring of bridge health from ambient vibration data. Journal of Vibration and Control, 17, 589. http://dx.doi.org/10.1177/1077546309360049

Marinin, A. V., Fedotov, V. M., Ostapenko, V. I., Serbin, V. A., Kuchkin, V. I., \& Ponomarev, Yu. K. (1978). Producing steel St3sp for plates. Metallurgist, 22(2), 114-115. http://dx.doi.org/10.1007/BF01087856

Mihir, C. M. (2011). Free vibration of tapered isotropic rectangular plates. Journal of Vibration and Control, 18 , 76. http://dx.doi.org/10.1177/1077546310396800 
Nurkan, Y., \& Sakman, L. E. (2006). Vibrations of a Rectangular Bridge as an Isotropic Plate under a Traveling Full Vehicle Model. Journal of Vibration and Control, 12, 83. http://dx.doi.org/10.1177/1077546306061411

Ponomarev, Yu. K., \& Ulanov, A. M. (2009). Finite element analysis of elastic-hysteretic systems with regard to $\begin{array}{lllll}\text { damping. } & \text { Russian } & \text { Aeronautics, } & \text { 52(3). Date }\end{array}$ http://dx.doi.org/10.3103/S1068799809030027

Ponomarev, Yu. K., Ermakov, A. I., Simakov, O. B., \& Mikhalkin, I. K. (2013). Metallic counterpart of rubber: A material for vibration and shock protection. Metal Science and Heat Treatment, 55(1-2). Date Views 17.04.2014. http://dx.doi.org/10.1007/s11041-013-9570-3

Ponomarev, Y. K., \& Kalakutsky, V. I. (2003). The multilayer all-metal vibration filters with elastic elements of a regular structure [Mnogosloinie celnometallicheskie vibroizoliatori s uprugimi elementami reguliarnoi strukturi]. Samara State Aerospace University, Samara, pp. 198.

Popov, E. P. (1986). The theory and calculation of the flexible elastic rods [Teoria i raschet gibkih stergnei]. Nauka, Moscow, pp. 296.

Popp, K., Lars, P., \& Walter, S. (2003). Vibration Damping by Friction Forces: Theory and Applications. Journal of Vibration and Control, 9, 419-448.

Ulanov, A. M., \& Ponomarev, Yu. K. (2009). Finite element analysis of elastic-hysteretic systems with regard to damping. Russian Aeronautics, 52(3), 264-270. http://dx.doi.org/10.3103/S1068799809030027

Yurddas, A., Ozkaya, E., \& Boyac, H. (2012). Nonlinear vibrations and stability analysis of axially moving strings having nonideal mid-support conditions. Journal of Vibration and Control, 20, 518-534.

Zhdanov, I., Staudacher, S., \& Falaleev, S. (2013). An advanced usage of meanline loss systems for axial turbine design optimization. Proceedings of the ASME Turbo Expo 6 A. http://dx.doi.org/10.1115/GT2013-94323

\section{Note}

Note 1. Power coefficient of similarity $\eta$ [eta] in (1) is definitely related with the introduced by E.P. Popov coefficient $\beta$ [beta], as a function of $\eta=f\left(\beta^{2}\right)$.

\section{Copyrights}

Copyright for this article is retained by the author(s), with first publication rights granted to the journal.

This is an open-access article distributed under the terms and conditions of the Creative Commons Attribution license (http://creativecommons.org/licenses/by/3.0/). 